of ammonium sulphate), with a trace of albumin. A further rovelty, and one which we approve, consists in supplying with che globules tablets or "peloids" as they are called, concaining various flavouring materials and condiments. Tastes differ widely as to the amount of condiment or flavouring which should be added to beef-tea or soup. By this device, however, each can satisfy himself. This step is particularly adrantageous in the case of invalids who often find a meat extract repulsive on account of an objectionable added flavouring. Lastly, it should be stated that the valtine globules are made of a size to admit of swallowing whole without any difficulty. In this way nourishment can be readily administered where extract in the form of beef-tea or soap is unsuitable.

\section{OREXIN TANNATE.}

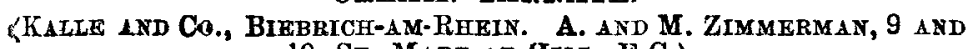
10, St. MARY-AT-HILL, E.C.)

Orexin tannate has been tried in the treatment of anorexia, as in phthisis, anæmia, and chlorosis, and in cases of atony of the stomach. It is a yellowish-white powder, not anlike calomel in appearance. It contains tannin in combination with "orexin," a base obtained by a synthetic mrocess from certain coal-tar derivatives. It is soluble in dilute hydrochloric acid and probably therefore in the Bastric juice. It dissolves also in alkali, according to our experiments, the solution turning a deep brown from the production of alkaline tannate. When the dry powder is weated in a tube it evolves a strong fishy odour characceristic of amines. Orexin tannate is said to be an excellent stomachic, stimulating the acid secretion of the stomach, encouraging its motor activity and materially shortening the process of digestion. The salt may be obtained in powdered form or in chocolate tablets, the latter containing $4 \mathrm{gr}$. of wrexin tannate.

(1) "GAIACOPHOSPHAL" AND (2) "PHOSPhOTAL."

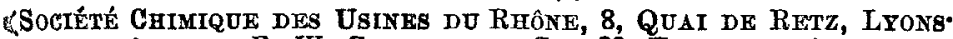
AGRN T: R. W. GREKFF AND Co., 20, EAstcheAP.)

These interesting bodies are new combinations of guaiaco and creasote respectively, which are stated to present distinct advantages over the compounds hitherto used. "Gaiacophosphal" is a definite white crystalline salt smelling distinctly of guaiacol. On treatment with potash the smell of guaiacol is more strongly developed. The salt readily melts on heating, and speedily dissolves in water. "Phosphotal" is a phosphite of creasote and is a gummy looking liquid with a creasote-like smell. On warming with potash the guaiacol evidently separates. Fxperiments are quoted to show the advantages of these compounds in contrast with the phosphates and combinations hitherto employed. As is well known guaiacol and creasote have been administered with encouraging results in some cases in phthisis, typhoid fever, \&c., and in respiratory disorders. These new salts are regarded as pharmacological improvements.

\section{EFFICIENCY OR COMPULSION ? To the Editors of THE LANCET.}

SIns, - A report which I recently made to my committee on the relation of vaccination to the recent small-pox epidemic at Middlesbrough has been criticised by $\mathrm{Mr}$. Alex. Paul in letters which he has written to various evening inapers, and is also referred to in an annotation in THE LANCET of July 23rd. I take this opportunity of forwarding you a copy of this report, which to my mind points out as has rarely been shown before the value and protection afforded by vaccination; it also clearly shows where the weakness of the present system of vaccination lies-i.e., in the inefficiency of most primary vaccinations and the want of systematic revaccinations. The State requires its servants, the public vaccinators, to practise vaccination in a prescribed manner, bout there is no such standard enforced in the cases of the numbers of children vaccinated by other medical practitioners who may and do exercise their own judgment as to whether they shall vaccinate a child in one, two, three, or wore places. How many medical practitioners are there in this country who always perform vaccination with the efficiency required by the Local Government Board of the public vaccinators? And what medical man is there who at one time or another, when a mother has brought her child to him for vaccination and has pleaded for "just one place or two small ones, Doctor," out of the kindly srmpathy of his heart has not vielded to this prayer in direct opposition to his better judgment?

Should not the Taccination Bill now before Parliament have clearly defined what constitutes an efficient vaccination and the period for which such protection lasts and have made suitable provision for seeing that such a vaccination was performed in every case? Mr. Paul in his letters expresses astonishment that there should have been 1207 vaccinated persons attacked with small-pox at Middlesbrough but how many of these 1207 can be considered to be really vaccinated persons-i.e., with scars of such an area and of such a quality as can be considered to be really protective and in whom the protection had not passed off through the lapse of time? We only know of 87 who had been revaccinated, leaving 1120 who had only had a primary vaccination. Of these 1044 were over the age of 15 years. If the 1120 were primarily vaccinated during the early months of infancy, as is very probable, then the 1044 cannot be classed as vaccinated persons protected from liability of attack, and the older they are the less is the protective or modifying value of the primary vaccination, this being most clearly shown in the table of deaths amongst the vaccinated class given in my report, the greatest mortality being at the greatest age periods.

The surprise at these results expressed by $\mathrm{Mr}$. Paul denotes that he either looks at the question from the point of view of the biased anti-vaccinationists who do not care to examine both sides of the question or that he, like a great majority of the inhabitants of this country, is utterly ignorant as to what constitutes a thorough and efficient vaccination and what is claimed for it as a protection against small-pox. One fine day does not constitute a summer nor does a vaccination consisting of one or two small scars afford protection for life against liability to attack from small-pox. It should be our duty as medical men, together with all other believers in the virtues of vaccination, to instruct the population on these points and the former should see to it that every child submitted to them for vaccination should be so vaccinated as to ensure its being rendered immune to attack. If this were so the populace would soon gain confidence in vaccination and there would be little need to discuss the question of compulsion. The anti-vaccinationists would not be able to point to the fact, as they have done in the past, that the majority of small-pox cases occur amongst a so-called vaccinated community.

I am, Sirs, yours faithfully,

Charles V. DrNGLE, M.D., B.HY. Durh., Medical Officer of Health of Middlesbrough.

July 25th, 1898.

\section{THE REPOR'T OF THE VACCINATION COMMISSTON. \\ To the Editors of THE LANCET.}

SIRs,-It is difficult to see what can be the object of the New Sydenham Society in simply reprinting the final report of the Vaccination Commission when it can be purchased of the Government printers at a very reasonable cost. But to print it without an index is still more inexplicable. It is a grave reflection upon someone-I do not know whether it may be the Commission itself or the Treasury - that it should have been left to General Phelps, the president of the Anti-Taccination League, to publish an index to the report of the Commissioners as well as to that of Dr. Collins and Mr. Picton. These two indexes may be obtained (1s. each) on application to General Phelps, Edgbaston, Birmingham. They are very fairly done. As to an abstract of evidence, that is much more worth the attention and expenditure of the New Sydenham Society, but it will need to be carefully done to be really useful and by someone who is pretty familiar with the vaccination controversy. What is much more practicable and would be rery useful and not very costly would be a consolidated index of the whole of the evidence. But that involves the Herculean labour of indexing the sixth volume, which, like the final report, was published without an index. It is understood that Lord Herschell has made an effort to get this latter defect remedied, but with what success I do not know.

I am, Sirs, yours faithfully,

Gloucester.

FRAXCIS T. BoND, M.D. Lond. 